\title{
Auxerre, la crypte de la cathédrale Saint-Étienne
}

\section{Christian Sapin}

\section{(2) OpenEdition}

\section{Journals}

\section{Édition électronique}

URL : https://journals.openedition.org/cem/862

DOI : $10.4000 /$ cem.862

ISSN : 1954-3093

\section{Éditeur}

Centre d'études médiévales Saint-Germain d'Auxerre

\section{Édition imprimée}

Date de publication : 15 août 2004

ISSN : 1623-5770

\section{Référence électronique}

Christian Sapin, « Auxerre, la crypte de la cathédrale Saint-Étienne », Bulletin du centre d'études médiévales d'Auxerre | BUCEMA [En ligne], 8 | 2004, mis en ligne le 13 décembre 2006, consulté le 22 septembre 2022. URL : http://journals.openedition.org/cem/862 ; DOI : https://doi.org/10.4000/cem. 862

\section{Ce document a été généré automatiquement le 22 septembre 2022}

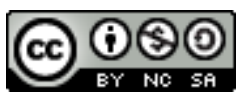

Creative Commons - Attribution - Pas d'Utilisation Commerciale - Partage dans les Mêmes Conditions 4.0 International - CC BY-NC-SA 4.0

https://creativecommons.org/licenses/by-nc-sa/4.0/ 


\title{
Auxerre, la crypte de la cathédrale Saint-Étienne
}

\author{
Christian Sapin
}

1 Les investigations sur les élévations intérieures de la crypte romane, construite dans le second quart du XI siècle par l'évêque Hugues de Chalon, ont repris au cours d'une campagne en juin 2003. Celle-ci a également entamé une reconnaissance des sols à l'extérieur de l'accès sud de la crypte. En effet, en 2002, nous avions montré que la salle centrale n'était pas accessible à l'origine par les escaliers construits à l'ouest, beaucoup plus tard à la fin du XI ${ }^{e}$ siècle, et que les accès se faisaient depuis le nord et le sud. $\mathrm{Au}$ nord, l'étude et le relevé du couloir nord/sud indiquent que sa modification au cours du XII siècle a fait disparaître les indices d'origine du moins de manière visible-; vers l'est, il ne semble pas qu'on puisse pénétrer directement dans le couloir du déambulatoire. $\mathrm{Au}$ sud, la fouille complète de l'espace transformé au XIII ${ }^{\mathrm{e}}$ siècle a permis de retrouver les structures des maçonneries romanes, sans que là encore on ne puisse certifier qu'un accès direct vers le couloir du déambulatoire était originellement possible. En revanche, des éléments de maçonnerie subsistant dans le mur ouest attestent un passage en symétrie avec celui du nord, dès le premier état.

2 Dans ce même secteur, des maçonneries antérieures à l'époque romane ont été reconnues. Il s'agit en particulier de la fondation d'un mur nord/sud formant retour vers l'ouest. Le mobilier recueilli en stratigraphie indique une occupation de l'Antiquité tardive (IV ${ }^{\mathrm{e}}-\mathrm{V}^{\mathrm{e}}$ siècles) et laisse supposer qu'il s'agit d'un élément d'une des premières cathédrales. D'autres fragments de maçonnerie en place également, antérieurs à l'époque romane, ont été retrouvés en poursuivant l'étude du blocage de l'entrée nord/ ouest de la salle centrale. Il est possible, à partir de ces éléments, de suggérer l'hypothèse d'un premier chevet d'une cathédrale initiale, bouleversé par les aménagements d'abord carolingiens, avec une première crypte attestée par les textes, puis par la construction romane de la crypte aujourd'hui conservée. D'autres investigations sont envisagées pour les années à venir dans ce secteur oriental de SaintÉtienne. 


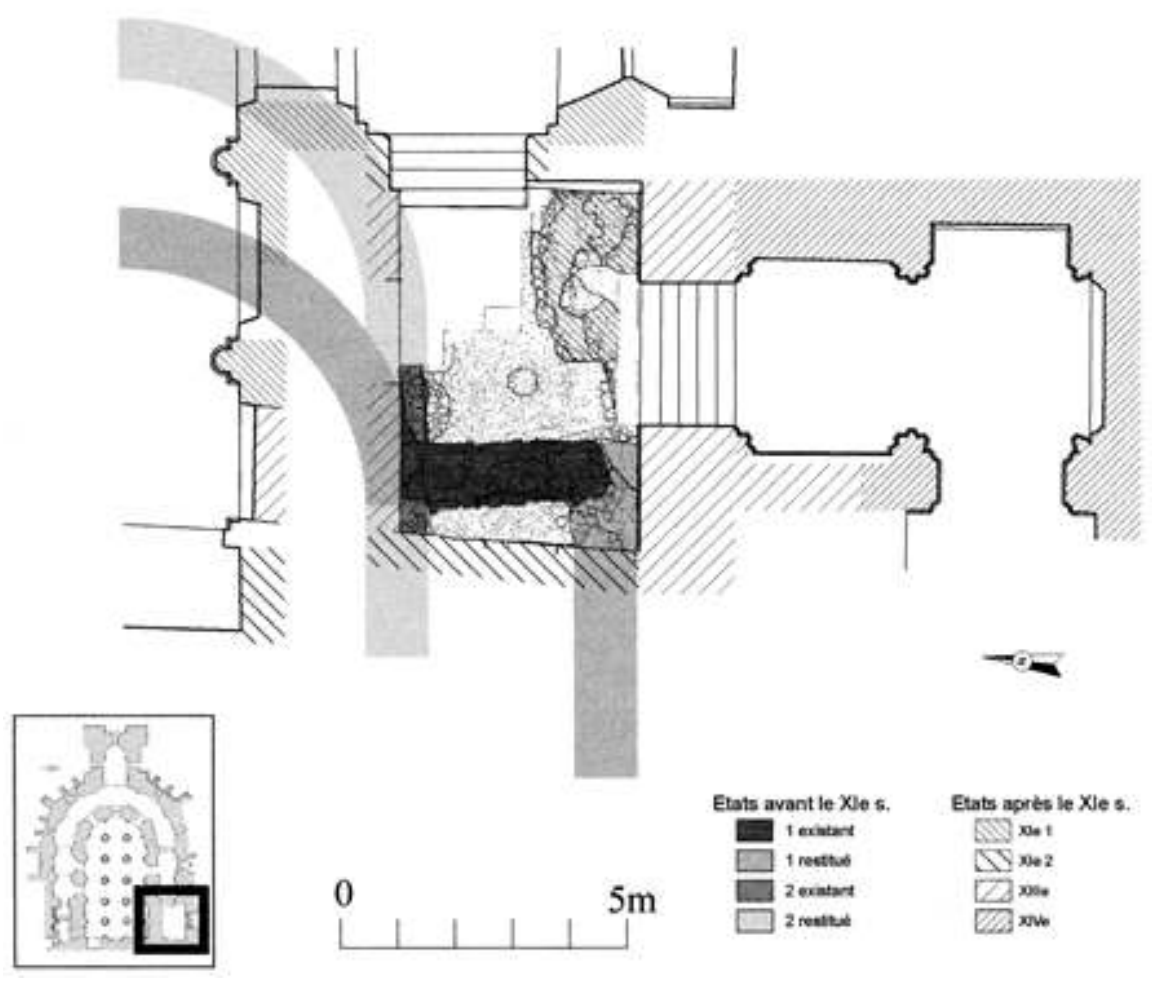

Auxerre, Cathédrale Saint-Etienne. Crypte, accès sud, plan du secteur fouillé (CEM).

\section{INDEX}

Index géographique : France/Auxerre

Mots-clés : crypte, cathédrale, Etienne (saint), Saint-Etienne d'Auxerre 